\title{
A FEASIBILITY STUDY OF ECONOMIC AND ENVIRONMENTAL SCENARIOS BY MEANS OF INTERACTIVE MULTIPLE GOAL PROGRAMMING
}

\author{
Jaap SPRONK* \\ Erasmus University, 3000 DR Rotterdam, The Netherlands \\ Frank VEENEKLAAS* \\ Scientific Council for Government Policy, The Hague, The Netherlands
}

\begin{abstract}
In this paper we describe our experiences with the application of a multiple criteria decision method (IMGP = Interactive Multiple Goal Programming) for the evaluation of economic policy in the Netherlands. An uncommon aspect of this study is that the multiple criteria decision method was not used to find an optimal solution, but rather to test the attainability of a number of contrasting scenarios for economic development. These scenarios are intended to represent the main options for the development of the Netherlands in the eighties. Within the framework of a broader research project (labeled Policy-Oriented Survey of the Future), these scenarios are linked to characteristic political views.
\end{abstract}

\section{Introduction}

In recent years, several attempts have been made to design and to apply interactive learning models in the area of economic policy and environmental management. In the present paper we describe a methodology and the main results of a study in the area of integrated environmental policy analysis. The purpose of the latter study is to evaluate different options for future economic policy in the Netherlands. Six characteristic views on society and its desired future, related to the main political forces in this country, have been formulated. As described in section 2, we make use of an economic model, which serves to evaluate and compare the implications of the aspirations of these characteristic views. As such, the use of econometric models with explicit behavioural relationships was rejected. The controversiality of these behavioural relations made the use of any specific model unfit to test the attainability of the aspirations of different views on society and its economy.

Because of earlier experiences [see Hartog and Spronk (1980)], interactive multiple goal programming in combination with an input-output model was applied.

\footnotetext{
*The authors are grateful to Professors Gerard van Driel, Peter Nijkamp and Piet Rietveld for their valuable comments on an earlier draft of this article.
}

0166-0462/83/0000-0000/\$03.00 (C) 1983 North-Holland 
As explained in section 3, we used an input-output model for the Netherlands which consists mainly of technical relationships and which has been formulated as a linear programming model. In this way, the model describes a set of technically feasible solutions. Of course, such a solution does not have to be feasible in practice, because institutional and social obstacles, not taken account of within the largely 'behaviour-free' model, might occur. Whether a solution is realized depends among other on the willingness of the members of society, on the degree of political consensus society can attain, and on external circumstances such as the development of world trade. In this sense, a characteristic view is a way of looking at the behaviour of society and its aspirations. By using interactive multiple goal programming [see Nijkamp and Spronk (1980), and Spronk (1981)], we were able to simulate the technical-economic consequences of the sets of goals adopted by each characteristic view.

It turned out that three different economic scenarios could be used to describe the differences between the technical-economic outlook of the six characteristic views. In a later stage of this project, these economic scenarios are tied with the different social, cultural, administrative and environmental issues inherent in the six characteristic views, so that, ultimately, six different images of future society result. To simulate the different economic scenarios, we used a set of goal variables and constraints which are described in section 4.

The values of these goal variables, which are generally different for different scenarios, have been imposed as constraints on the set of feasible solutions. This has been done in an interactive and systematic way, raising the values of the goal variables and, in consequence, reducing the set of feasible solutions.

In section 5, we present and discuss some of the results of this study. In section 6 , we make some observations with respect to the process of using a multiple criteria decision method and with respect to the quality of the results, as perceived by the users. Finally, in section 7 , we describe the main conclusions of this study.

\section{Framework and purpose of the study}

The Netherlands Scientific Council of Government Policy (Wetenschappelijke Raad voor het Regeringsbeleid - WRR) is an independent advisory body which is engaged in studying developments which influence society in the longer term and which tries to identify potential problems and conflicts of interest in Government policy. As such, the Council tries to clarify the decisions to be made by the policy-makers, and the implications of these decisions. In principle, the WRR may address itself to any subject it deems relevant for Government policy. In general, the 
subject is approached from a number of view points: apart from the longterm prospects, the Council is primarily interested in the links between different policy areas and in the overall coherence of the Government plans. The main reason to pay much attention to this coherence is that the continuing increase in the amount of Government responsibilities runs the risk that different policy-makers hamper each other's intentions and that real problems are identified too late.

In the Netherlands, but also elsewhere, instruments are being sought which could improve the quality of policy by identifying latent as well as manifest problems and by distinguishing between the permanent and the temporary. As a result of this, 'think tanks', such as the WRR have been created in many countries to assist in the preparation of Government policy. In particular, attention is being paid in the WRR to differences in policy views [cf. WRR (1982)].

Each characteristic policy view includes a set of aspirations. To construct, for each characteristic view, an image of the future which is merely a projection of the aspirations concerned would be little informative and rather naïve. The use of econometric models for the evaluation of the feasibility and consistency of these aspirations is hindered by the fact that the views differ fundamentally, not only with respect to the aspirations but also with respect to the presumptions about basic economic and social relations. This means that most of the econometric models in use are not fit to test the different views for inconsistencies or technical feasibility. Econometric models normally imply a (large) number of behavioural presumptions which are often already part of political controversies. Of course, most models contain relations and constraints with respect to which little or no disagreement does exist. But after a closer examination, their number turns out to be few. In the field of economics, there is a fair amount of consensus with respect to technical relationships: ore and coal are needed to produce steel, steel is needed to build ships, etc. For production, capital and labour are necessary in amounts which are rather stable (in the case of capital) or decrease in time with a largely autonomous rate (in the case of labour). Capital goods wear out and have to be replaced after a certain time. In principle, these relations between and within different sectors of the economy can be represented by means of an input-output model. Experiences with an earlier study for the WRR [see Hartog and Spronk (1980)], in which an input-output model without any behavioural relations was used, and which turned out to be fruitful, contributed to the adoption of the same methodology in the present study.

\section{Methodology}

The ingredients of the methodology used in this study are an input-output 
model, a set of goal variables and an interactive multiple criteria decision method. The goal variables will be described in section 4. An earlier version of the input-output model has been described elsewhere [see van Driel et al. (1980)] as is the interactive procedure IMGP = Interactive Multiple Goal Programming [see Nijkamp and Spronk (1980), and Spronk (1981)]. Here, only some general features will be outlined. At the end of this section we will show how these ingredients have been put together.

The basis of the input-output model used was a dynamic (10-period) sectoral input-output model designed for a major industrial heartland in Western-Europe, made up by the areas of the Netherlands, Belgium, Nordrhein-Westfalen and the North of France. For our study, this model was updated, and adapted to the Dutch situation. Other than technical relations were not included. In addition, a number of constraints was adopted (see below and section 4). These constraints limit the rate of change of certain variables and, in consequence, the behaviour of the actors in the system. However, we took care to choose these limiting values in such a way that controversions on these values are hardly probable.

The structure of the input-output model can be formalized by means of the following inequality conditions:

$$
x_{t} \geqq(A+D) \cdot x_{t}+K \cdot\left(w_{t+1}-w_{t}\right)+f_{t}+h_{t},
$$

where

$x_{t}=$ vector of sectoral production levels in year $t$,

$w_{t}=$ vector of production capacities in year $t$,

$f_{t}=$ vector of final consumption per sector in year $t$,

$h_{t}=$ vector of export surpluses in year $t$,

$A=$ matrix of technical coefficients,

$D=$ matrix of sectoral depreciation coefficients,

$K=$ matrix of sectoral capital coefficients.

In addition to these relations, constraints were formulated with respect to production capacity (production cannot exceed capacity; overcapacity, capacity expansion and capacity demolishment are limited), with respect to consumption (minimum and maximum levels for the growth rate of consumption per sector) and with respect to the export surplus (the yearly changes in the sectoral trade balances are limited). Apart from 17 conventional sectors, three sectors of a somewhat uncommon nature were included: (1) a job creation sector, (2) an energy savings sector and (3) a pollution abatement sector.

The interactive procedure used in this study, Interactive Multiple Goal Programming, works in broad lines as follows. During the interactive process, constraints on the values of the goal variables are formulated and the right-hand side value of these constraints are changed one by one from 
iteration to iteration. To be more precise, the process starts by presenting a vector of minimum goal values to the decision-maker, together with a set of indicators of the potential improvements, within the set of feasible solutions, of these minimum goal values. (For the case of presentation we assume all goal variables are to be maximized.) In the first iteration, very low minimum goal values are chosen (viewed by the decision-maker as absolute minimum conditions or even worse) in order to be sure that no potentially acceptable solutions are excluded. The decision-maker has to indicate whether or not the solutions meeting the minimum requirements are satisfactory. If so, he can choose one of these solutions. If not, he has to indicate which of the minimum goal values should be increased. On basis of the new vector of minimum goal values, a new set of indicators of the potential improvements of these values is calculated and presented to the decision-maker. The decision-maker has to indicate whether the shift in the indicated minimum goal value is outweighted by the shifts in the potential values of the other goal variables. If so, the decision-maker gets the opportunity to revise his earlier wishes with respect to the changed minimum goal value. If not, the change of the minimum goal value is accepted and the decision-maker can continue to raise any of the other or even the same minimum goal value. Of course, by raising the minimum goal values, the set of feasible solutions is reduced. The decision-maker thus has several options. He can continue until the remaining set of feasible solutions becomes very small. Another possibility he has is to select a suitable solution from the set of solutions satisfying the minimum conditions (For instance, the used interactive method produces at each iteration among other things a set of Pareto-optimal solutions.) Finally, a set of feasible solutions satisfying the minimum conditions on the goal values can be subjected to a second analysis by the decision-maker. In his decision environment, the decision-maker may wish (or need) some elbow-room, thus requiring more than just one solution.

Alternatively, it may be that not all goal variables have or could have been included in the first analysis. Then, given the sets of solutions resulting from that analysis, the goal variables which have been neglected there can be taken account of in the second analysis. In fact, this was done in the WRRstudy in which we took part. By means of the interactive procedure, a set of solutions satisfying certain minimum conditions on the goal values was found. Then, this set was further investigated in order to take account of the instruments by means of which these solutions could be fulfilled. This second analysis also involved additional objectives and other instruments than in the first analysis. In this second analysis, attention was paid among others to the time paths of the most important instruments and to the sectoral structure of the economy. In the latter case, more detailed objectives concerning the expansion or contraction of particular sectors (e.g., Government services) emerged. 
The main message of this paper is to be found in the way in which the described ingredients have been combined. Remember that the input-output model used included technical relations and some generally accepted political constraints only. This means that both these technical relations and the constraints are rather 'hard', implying that — if a solution is not feasible within the model - this solution is certainly not feasible in the real world without major changes in technology. On the other hand, a solution which is feasible within the model may or may not be feasible in the real world, depending on the behaviour of the economic agents, which was deliberately not described by the model. Next remember that at each iteration of the interactive procedure, a minimum value is required for each of the goal variables. We can now follow a similar reasoning as described above. A solution, which meets the conditions on the goal variables and does not violate the other constraints, may or may not be feasible in the real world.

On the other hand, if we cannot find such a solution within the model, we can be sure that, in the medium-run, the combination of the goal variables as stated in terms of the minimum goal values, is not feasible in the real world. In this sense we have a tool to 'falsify' political aspirations: By using the interactive procedure this can be done systematically. An additional feature of this methodology is that, given a set of solutions satisfying a certain combination of conditions on the goal values, one can trace back a set of corresponding conditions on the instrumental values. For instance, a minimum condition on the goal variable might imply a certain minimum value on capital investment. Clearly, the latler minimum value would then be a necessary but not a sufficient condition.

\section{Scenarios, goals and constraints}

\subsection{Three scenarios}

On the basis of the already mentioned characteristic views on society, three contrasting scenarios, under the headings Balanced Growth, Export-led Growth and Voluntary Austerity can be identified. Each of these developments has backing in the Dutch society as being desirable and/or necessary courses to meet the problems of the eighties. Below, these scenarios are presented briefly in their main features, together with the arguments advocates of each line of development put forward.

Balanced growth. Characteristic of this scenario is a balanced development of the consumption in the different sectors, taking account of shifts of preferences over time.

Because of the educational composition of the present and the future working population and because of the historical trend in consumptive 
preferences, the growing share of services in the national product is expected to grow. The share of services in total consumption rose in the Netherlands from $63 \%$ in 1975 to $67 \%$ in 1980 . In the view of this scenario one tries to go along positively with these tendencies; no use trying to stem the tide. In this view, the Netherlands are not exceptionally well fit for a large sector of heavy industry. The lack of space, the extraordinary high population density and the absence of a big domestic market being the main negative factors. Of old, trade, transport and communications, and the lighter processing industries such as food are the sectors in which the Netherlands has been able to exploit well its geographic location and in which a substantial amount of know-how and competence has been built up. In sectors such as tourism, insurance and banking a growth potential is present. With the exception of trade, tourism and transport, the service sectors contribute little to the balance of trade. Therefore, agriculture and (light) industry (metal products, electronics, food) remain necessary to cover the import needs.

In this view, the main goals are the growth of consumption and the reduction of unemployment. The relative weight given to each of these goals changes with different political points of view. Pollution and balance of trade function as limiting conditions. In this view, there is no reason to treat energy different from any other marketable good. Limitation of the use of energy is no goal in itself, but it can be relevant by contributing to an equilibrium of the balance of trade.

Export-led growth. This scenario stresses, more than the previous one, the key position of the industrial sector for economic development. The high growth rates in production, the large contribution to the overall balance of trade and the positive effects on complementary employment in commercial services make that a vital industrial sector is the crucial factor to overcome the present stagnation. This means a reversal of the trend of the last 15 years which showed a dismantlement of some sectors of the Dutch industry, such as shipbuilding, textiles and leather. The consequences of a policy aiming at an internationally competitive economy are simulated by demanding a substantial overall export surplus during the considered period of 10 years. This surplus can be used for additional imports of consumer goods. That's why an initially more unbalanced sectoral consumption pattern than in the preceding scenario is acceptable. As a consequence, this scenario can be expected to simulate ongoing international specialization. Exceptions are made for those sectors where no import compensation is realistic: government services, education, health-care and real estate services. For consumption in these sectors no decline is allowed; for all other sectors a lower limit of $-4 \%$ a year is set.

Like in the Balanced Growth scenario, total domestic use of energy is only relevant in relation to the balance of trade. With respect to pollution, a 
somewhat more pliable attitude is presumed. The relative accent on maximization of consumption or employment is subject to political appreciation.

Voluntary austerity. In the wake of studies as 'Limits to Growth' of the Club of Rome (1972) and other reports in which the danger of pollution and the threatening exhaustion of raw materials and non-renewable energy by ongoing economic growth was stressed, the concept of 'a sustainable society" won the support of a growing number of people. In the Netherlands, this concept found a response in the appearance of a large number of so-called 'action groups' as well as within the parliamentary political life. Although it does not necessarily imply zero-growth, this view attacks the blind acceptance of the growth in consumption (especially the ever-increasing consumption of 'luxury goods') and the use of wasteful methods. Instead, basic needs such as housing, food and public transport should have priority and the production should be directed more on products with a long lifespan and less raw material input. Consumption-level and -pattern are not ultimate goals but become means put at the service of sustainability.

Contrary to both other scenarios, reduction of energy use and pollution are central goals, while level and pattern of consumption are interpreted as limiting conditions. Also, a structural export surplus is demanded, not to be used - as in the Export-led Growth scenario - for domestic consumption, but to increase the level of foreign aid.

\subsection{Goals and constraints}

The above introduction of the main characteristics of the three scenarios selected for further analysis, make clear that the differences in aspirations cluster around a limited number of issues: consumption, employment, balance of trade, energy and pollution. These five issues are specified by means of seven goal variables, as both the consumption and energy have been translated by means of two goal variables. Below, we will describe the goal variables and constraints used in this study. Necessarily, we have to be somewhat bricf. For a more detailed discussion, we refer to the final reports on this project [Van Driel et al. (1982), and WRR (1982)].

Employment. By substracting the labour demand from the labour supply, the level of unemployment for each year is calculated. The labor demand per sector is equal to the production value times a monotonously decreasing labour quote. The rate of decrease of the labour quotes differs for each sector. These decreasing labour quotes represent labour saving technical progress. Capital productivity is assumed to be constant in time. Labour supply is an exogenous variable, calculated on basis of demographic trends 
and trends in participation rates. To warrant a certain stability on the labour market not total unemployment but the largest unemployment level in any year is minimized. The choice of this minimax format has certain implications for the interpretation of the results, to which we will return in the next section.

Consumption pattern. Analogous to employment, the goal of a balanced consumption pattern is formulated in a maximin format: maximize the smallest growth rate in any year and in any sector. In order to take account of observed shifts in preferences, the growth-rates are weighted by the sectoral income-elasticities.

Total consumption. By maximization of the smallest growth rate, a balanced (albeit downwards) growth pattern is granted but the consumption possibilities will not always be sufficiently exploited. By raising the lower limit for the minimal growth rate, the possibilities to realize overall consumption growth are squeezed. To elucidate this conflict, the goal of maximization of total consumption for all years for all sectors was added.

Balance of trade. This goal is defined as the minimization of the sum of trade balance deficits over all periods. The possibility to compensate one year's deficit with another year's surplus is left open. Furthermore, this goal has been formulated in a way which makes it possible to strive for a structural surplus.

Energy use. This goal has been defined as the minimization of total domestic use of energy both for consumption and production, minus the amount saved by increased efficiency in the use of energy. Within the model, the saving of energy has been made possible by adding to the seventeen conventional economic sectors of the model an energy saving sector. The output of this sector can be interpreted as the savings realized by using alternative technologics for the use of energy. Its yearly growth is limited to a value equivalent to $1.5 \%$ of total energy use in the base year. Energy use is defined in physical terms (PJoules) and calculated by adding up energy quotes times production per sector. The energy quotes are constant in time but vary (up to a factor 30 ) between sectors.

Energy incorporated in consumption. Optimization of the above energy goal can lead - as far as the balance of trade permits - to a decrease in the production of energy-intensive export goods and a simultaneous increase in the import of goods with a high energy content. In other words, by importing plastics from Hong Kong the energy problem lies in Hong Kong and is not ours any more. This view is not contradictory with the first two 
scenarios, where energy is a marketable good as any other. But the last scenario formulates its goal of sustainability and saving of exhaustable raw materials in global terms. Therefore, in this scenario, a goal on energy use defined as the total amount of energy incorporated in domestic consumption is relevant. This amount is calculated by adding up the products of the cumulated energy quote times the consumption per sector.

Pollution. To take account of pollution, the model has been extended with a separate pollution-abatement sector. Target values for unabated pollution are set, starting from the observed level of pollution in the base-year to zero in the tenth year. The sum of pollution in excess of these target values is minimized. Pollution is related to the level of productive activity in each sector as well as to some of the sectoral consumption levels. Only the kinds of pollution, for which techniques and costs of abatement are known, are taken into account.

In addition to these goals, a number of constraints has been formulated; some of them being of logical nature, others representing reasonable limits to the rate of change of some variables. Notably the yearly changes in the balance of trade per sector may not exceed $5 \%$ of the value of import or export (whichever is bigger) in the base-year. Production in each sector is always equal or less than the capacity in the year before. The growth of capacity is limited to $10 \%$ a year. The same limit holds for the growth of sectoral consumption. Dismantlement of capacity is limited by the rate of depreciation.

\section{Results}

In this section, we will illustrate how the three scenarios have been simulated by means of the methodology described in the preceding section. First, we give an overview of the simulation of the scenario which has been described as Voluntary Austerity. Next, we describe the final results of the two other scenarios. We conclude this section with a global comparison of the results.

Table 1 gives the starting goal values of the Voluntary Austerity scenario. The imposcd goal constraints arc not very restrictive, which cxplains why the separate optimization of each of the goal variables results in rather favorable goal values. Unemployment, for instance, can become less than only 66,000 manyears from the third year on (compared to 270,000 in the starting year). Consumption growth can become - under maximization of this goal variable - about $4.5 \%$ a year on average and the average level of the domestic use of energy could become, during the eighties, only two-thirds of the level of 1980. In the last two columns of table 1 , the 'worst' and the 'best' 


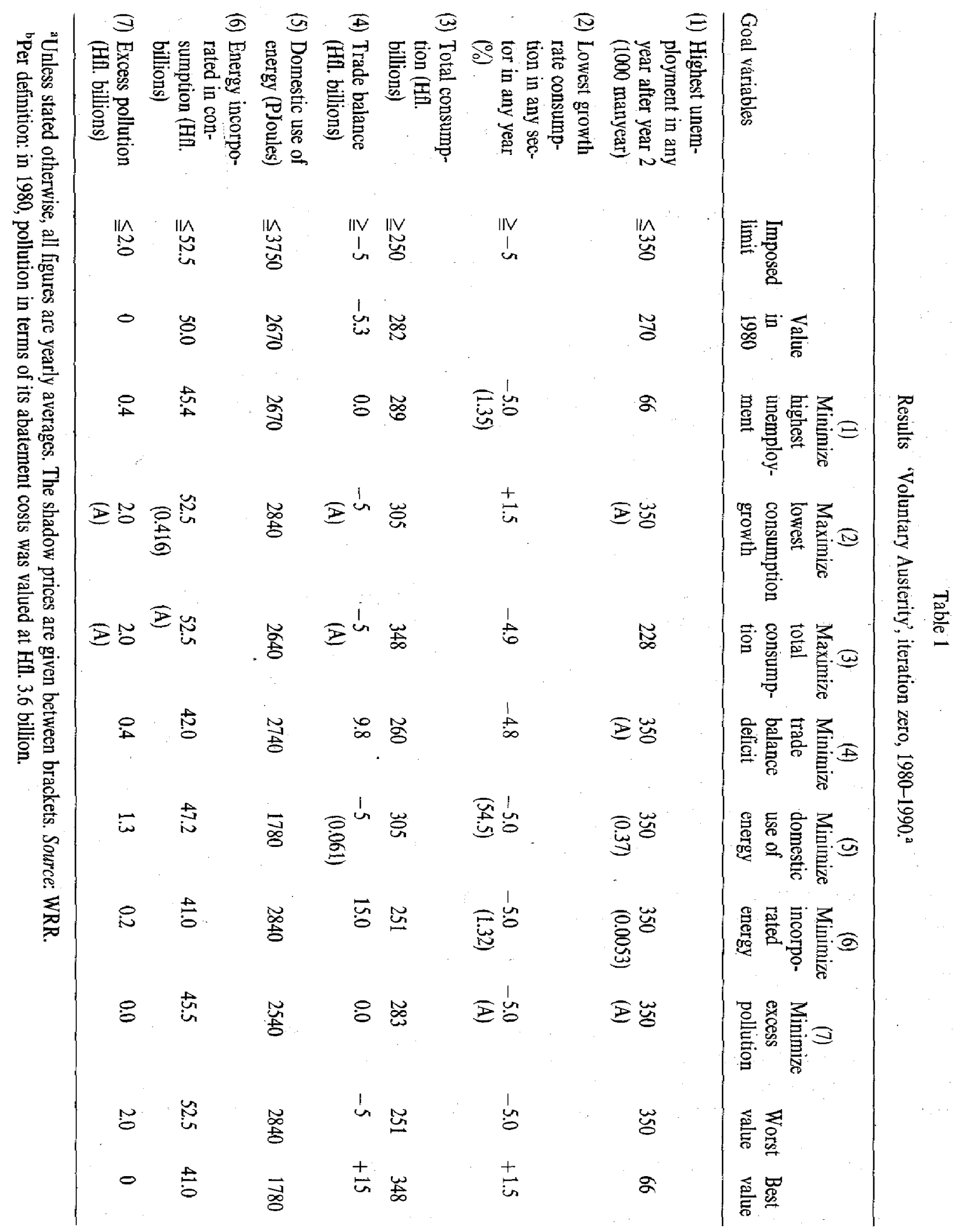


goal values are given. Because of the rather unrestrictive goal constraints, these values differ still wildly.

Another feature of this (and normally any) starting table is the low frequency of non-zero shadow prices. These shadow prices indicate that the imposed goal constraints are effective: relaxation of any of these constraints by one unit would make it possible to improve, at least locally, the optimal goal value by the precise value of the shadow price. The dimension of the shadow price is the dimension of the optimized goal variable divided by the dimension of the constrained goal variable. In the case of this starting table: loosening the minimally required yearly growth rate of consumption from $-5 \%$ to $-6 \%$ would make it possible to lower the maximum unemployment level by 1350 manyears.

Sometimes a goal constraint is effective but other solutions are possible with exactly the same value for the optimized goal variable. In such cases, no shadow price appears and the effectiveness of the goal constraint is indicated by an A: Alternatives present.

As can be concluded from the two last columns of table 1, the set of feasible solutions is still large. In the subsequent six iterations, the goal constraints have been tightened (thus reducing the set of feasible solutions) to get less extreme solutions and in order to get a better insight in the trade-offs between the various goals. At each of the six iterations, one of the goal constraints was adjusted, after which each of the goal variables was optimized again. Fig. 1 shows the impact of this subsequent tightening of goal constraints on the attainability of other goals. Next, we will describe each of the iterations in some more detail:

(0) (See table 1.) The highest unemployment level after the second year may not exceed 350,000 manyears; the minimal (weighted) growth rate of the consumption in any sector in any year should equal or exceed $-5 \%$; the average level of consumption in the eighties is not allowed to be more than $11.5 \%$ below the level in 1980 ; the overall deficit on the balance of trade should, on average, be less than Hfl 5 billion a year; the average level of the use of energy in the eighties should be less than $12.5 \%$ above the 1980-level; the average level of the energy incorporated in consumption should be less than $5 \%$ above the 1980-level; and the average annual excess of the norm for pollution should be lcss than Hfl 2 billion in terms of its abatement costs.

(1) The last requirement is tightened to a maximum of Hfl 5 billion abatement costs in excess of the pollution norm.

(2) The domestic use of energy is limited to an average level in the eighties of $12 \%$ under the 1980 -level.

(3) The average level of energy incorporated in consumption should on average be $10 \%$ less than the 1980-level. 

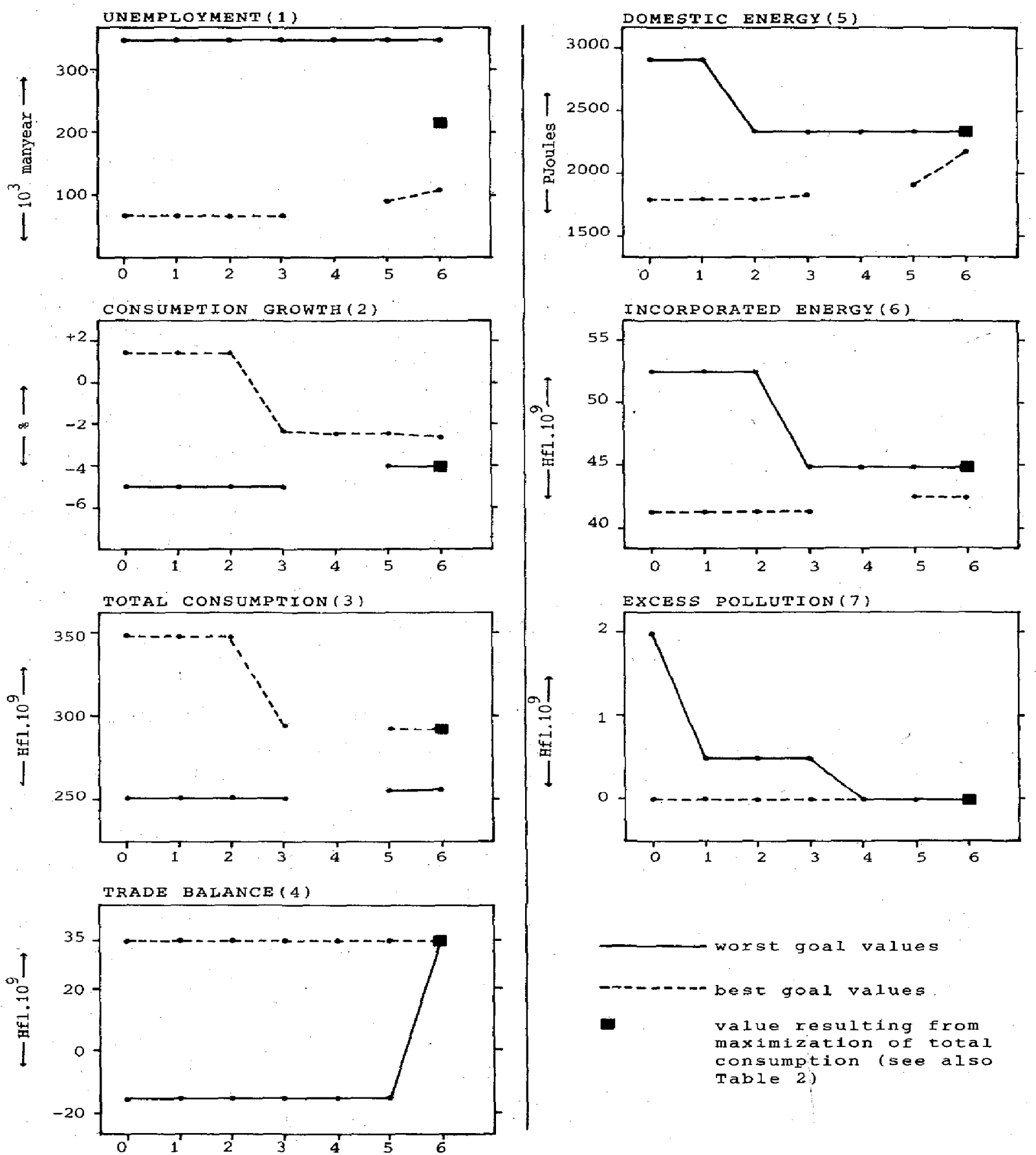

Fig. 1. Worst and best goal values during the iterative process, Voluntary Austerity. 
(4) No excess of the target values for unbated pollution is accepted.

(5) The minimal growth rate for the sectoral consumption level in each year is increased from -5 to $-4 \%$.

(6) A structural surplus of Hfl 3.5 billion on the balance of trade is required for the benefit of foreign aid.

Table 2 presents the final results of the simulation for the five most relevant goals of this scenario. As expected, more shadow prices have become non-zero. Moreover, the average value of these shadow prices has increased. It turns out that the requirement of minimal sectoral consumption growth is 'expensive' in terms of the other goals. Even more expensive is the upper limit set on the energy incorporated in consumption. By raising this upper limit, the values for employment, consumption and, surprisingly domestic use of energy could be improved considerably. But, as pointed out before, this would strike the heart of this scenario. Furthermore, the final table shows that a substantial decrease in use and consumption of energy and a lowering of the norms for pollution will be within reach, at least technically, within the following 10 years. That is, if no further growth in the level of consumption is accepted. In addition, the composition of the consumer's basket would then have to undergo some drastic changes. For example, a yearly four percent decrease of the consumption of energy would become necessary.

The growth of the labour supply in this scenario is assumed to be smaller than in the two others (a yearly growth of 15,000 manyears vs. one of 50,000 manyears) and underestimates the factual growth in the labour supply during 1981 and 1982, which equals 70,000 manyears per annum. Background of this presumption is that in case of a development in the direction of voluntary austerity, less emphasis is put on the 'formal economy'.

Tables 3 and 4 show the final results of the two other scenarios. The first remarkable difference with the scenario discussed above is that if constraints on energy and pollution are absent or less restrictive, a growth of total consumption of $2.6 \%$ (Export-led Growth) to $3.1 \%$ (Balanced Growth) a year is feasible. Production growth must be higher because the share of investments in total expenditures increases and, in the case of export-led growth, because the export surplus is positive. Because of saving activities, the use of energy is moderate in both growth-scenarios: the level in the eighties ranging from $109 \%$ to $82 \%$ of the 1980 -level. Note that in both scenarios, energy saving is not a goal in itself. However, it is stimulated by the goal to ensure no deficit on the balance of trade. In both growth scenarios, unemployment can be brought down to acceptable levels, be it at the expense of all other goals. That is, if the other goals are pursued, the limitation of uncmployment bccomes a binding constraint, though its shadow prices are not high. For instance, increasing the acceptable maximum unemployment level by 1000 manyears results in an increase of consumption by 6 to $7 \mathrm{Hfl}$ million a year. 


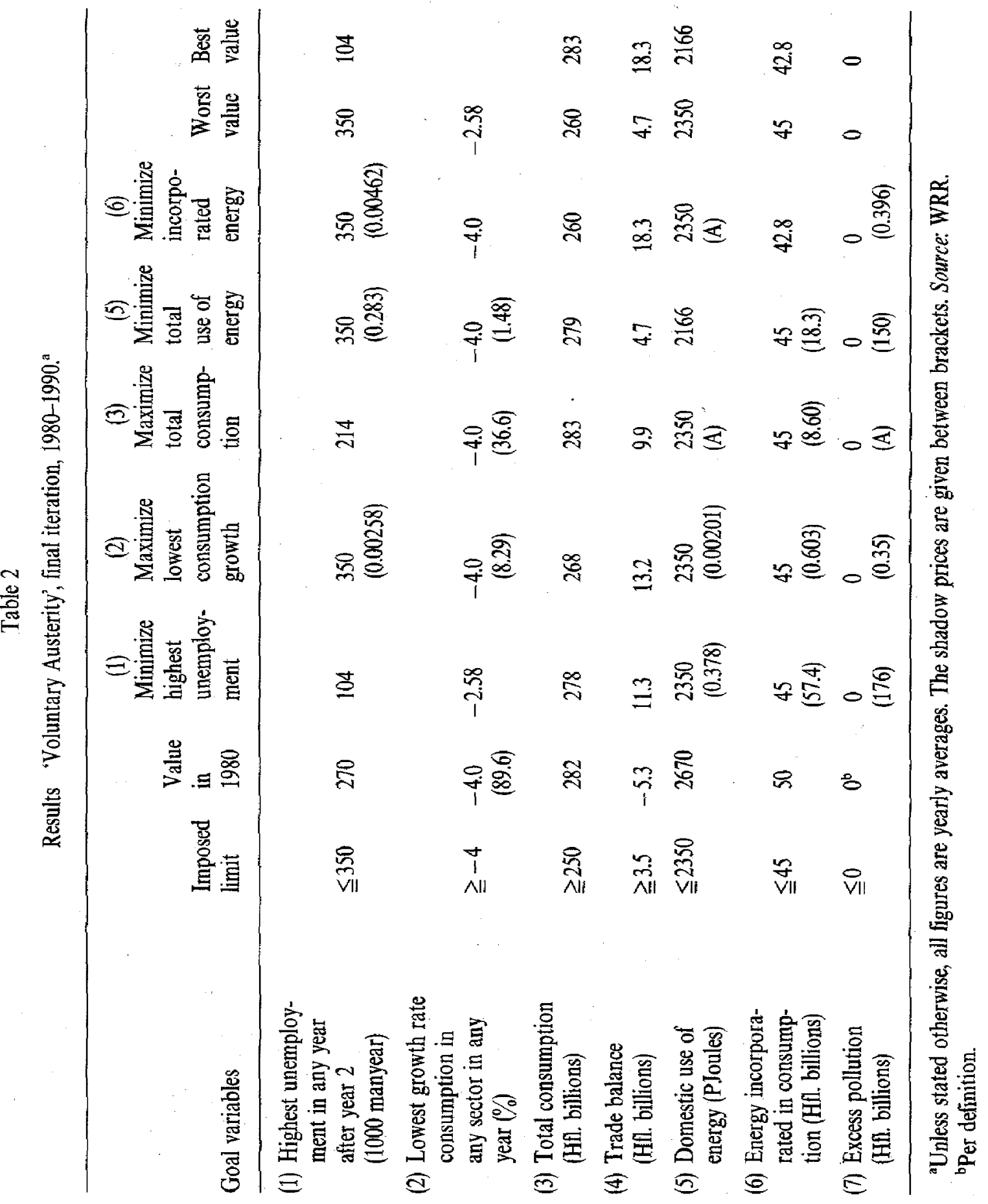




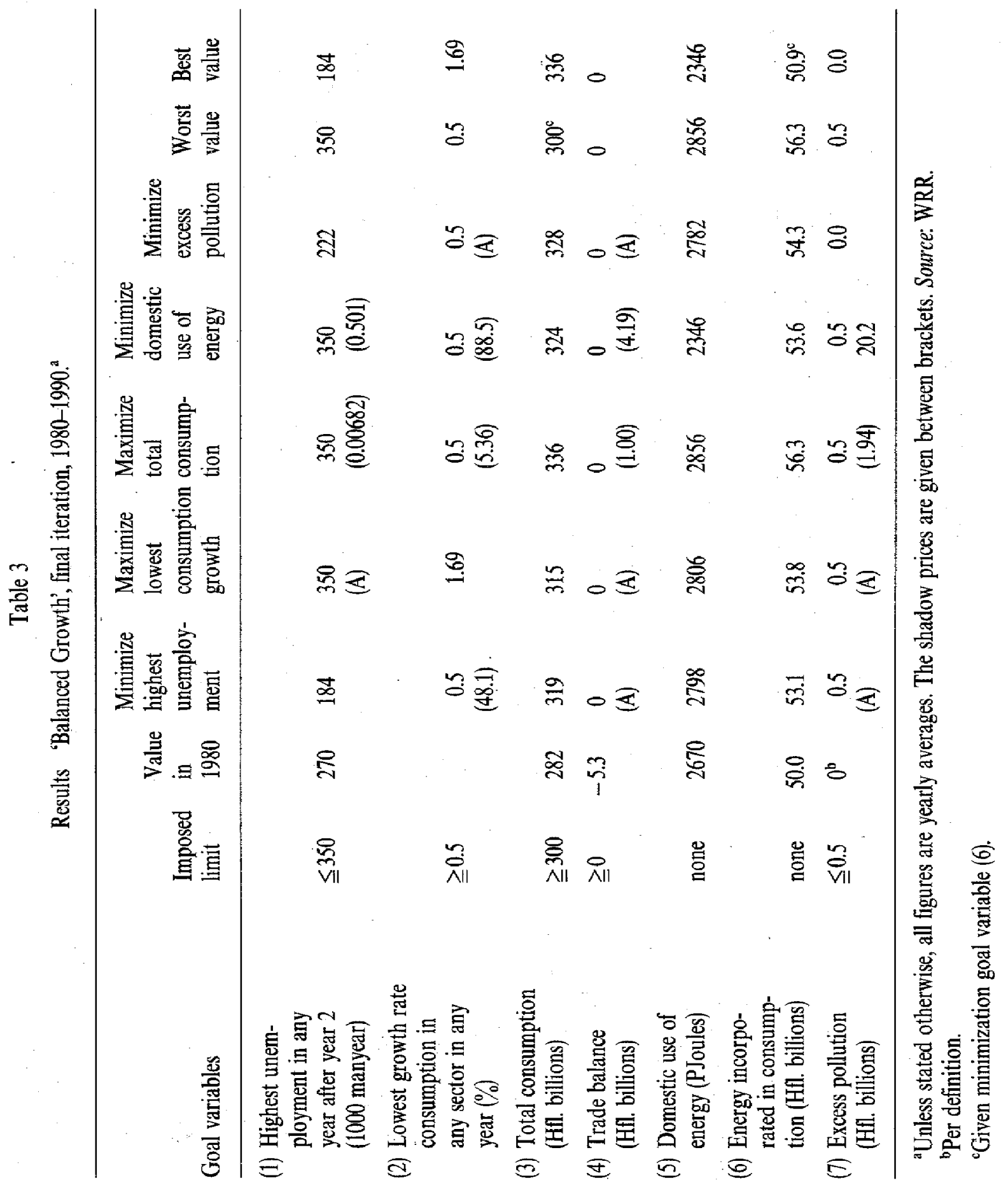




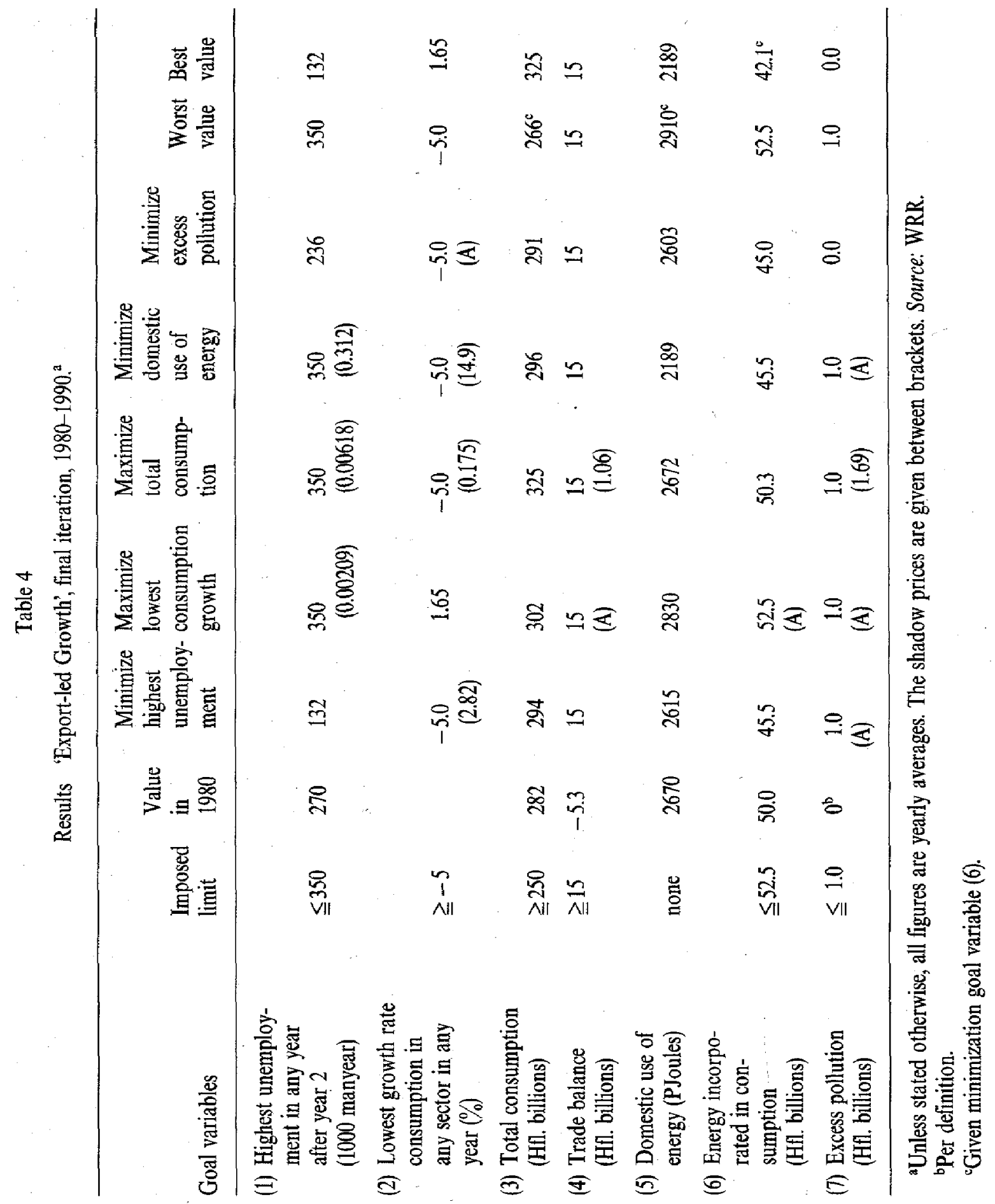


It is remarkable that, even with a yearly increase of the labor supply by 50,000 manyear (about $1 \%$ of the working population) and an ongoing labour productivity growth, an effective decrease of unemployment is technically feasible, while high growth-rates for consumption, say over $4 \%$ a year, are not. Furthermore, moderate growth and stabilization of energy use can go well along, as is the case for the limitation of (abatable) pollution. A substantial decrease in the use of energy, in particular of energy incorporated in consumption, can only be realized by adapting the level and composition of consumption. As more detailed analysis of the results of the voluntary austerity scenario shows, a high level of net investments would be an additional requirement.

Many more observations can be made on the differences with respect to the sectoral structure of the economy, the developments in time, investment requirements etc., but in this paper we will suffice with this brief overview of the economic results. In the next section, we will make some observations of a more technical nature.

\section{Some observations}

A large part of this study has been devoted to the formulation of the goals and to the associated adjustments of the model.

In an earlier, partly similar study [see Hartog and Spronk (1980)], we learned that the goals and constraints which are important within different views, cannot easily be identified - particularly not prior to the actual use of the model. Of course, official reports and documents do exist which may give some indications but these are often defined in a fuzzy way and left open to different and possibly conflicting interpretations when operational goals and constraints have to be formulated. In the present study, some time was spent to discuss and to test different goal formulations, e.g., with respect to consumption, energy use and pollution. However, the model revisions that became necessary because of the very goals chosen, were the most labourintensive. Note for instance, that several artificial sectors had to be added to the model.

As in other studies, it turned out that not all goals and constraints can be made explicit prior to the actual interactive process.

At each iteration, an enormous amount of data was produced. It turncd out, that the users were not only interested in the goal values resulting from the seven optimizations per iteration (see tables 1,2,3 and 4), but also in the values of the instrumental variables leading to these goal values. That is, for each optimal solution, the user had to evaluate four $(20 \times 10)$-dimensional matrices (20 sectors for 10 years) relating to energy use, employment and unabated pollution. In the discussion of these results, policy considerations not yet accounted for in the a priori defined goals appeared to play an 
important role. Especially the time paths of the instrumental variables received much attention. In principle, policy considerations emerging during the interactive process could have been formulated as separate goals to be added to the set of already defined goals. Practically however, it was easier to take account of these additional considerations in an ad hoc manner, among others because they appeared to differ considerably between different scenarios and because we did not want to increase the number of goal variables too much.

The model used in this study has 20 sectors and 10 periods. The five issues which had to be investigated (unemployment, consumption, energy use, trade balance and pollution) are of course important for any sector in any period. It would be impracticable to formulate for each of the issues and for each sector in each period a separate goal variable. That's why we used goal variables which are to some extent aggregates of a large number of similar goal variables. An example is the minimax formulation which was used several times in this project. The use of these minimax formulations can be compared with snake-catching: one can firmly hold the snake's head but it is difficult to control, at the same time, the other parts of the snake's body. For consumption, we have tried to solve this problem by adding a separate goal variable for total consumption which could be confronted with the maximization of the smallest growth rate of consumption in any sector in any year.

In summary, a largely behaviour-free input-output model for the Netherlands was used in combination with interactive multiple goal programming to test the feasibility of three different scenarios for the economic and environmental development of the Netherlands in the eighties. The described methodology can be used to 'falsify' different political aspirations inherent in the scenarios. That is, because the input-output model includes highly reliable relations only, one can be rather sure that, once a particular combination of goals is not feasible in the model, it will not be feasible in the real world either. However, a combination of goals which is feasible within the model is not necessarily realizable in reality. Nevertheless, from such a feasible model solution, some necessary conditions for its realizability in practice can be deduced.

The main use of the methodology is that it provides an important learning tool, both for decision-makers and analysts. In this application, the methodology proved to be fruitful because results were produced which are not trivial but are nevertheless explicable afterwards. For example, it was found that the voluntary austerity scenario requires gigantic investment, among others to safeguard the employment targets. Furthermore, it turned out that the export-led growth scenario and the inherent industrialization had less effect on employment than expected. In fact, these non-trivialities are examples of 'falsified aspirations' as mentioned in section 3 . 
Another use of the methodology is that it can serve as a flexible means of communication. This is witnessed by the fact that the results of this study are elaborated and reported in an official document of the WRR (the Netherlands Scientific Council of Government Policy) which is intended to stimulate political discussion in the Netherlands.

\section{References}

Driel, G.J. van, J.A. Hartog and C. van Ravenzwaaij, 1980, Limits to the welfare state (Martinus Nijhoff, Boston, MA).

Driel, G.J. van, C. van Ravenzwaaij, J. Spronk and F.R. Veeneklaas, 1982, Achtergrondstudie bij BTV-II (Staatsuitgeverij, Den Haag) forthcoming.

Hartog, J.A. and J. Spronk, 1980, Een modelstudie naar de relatie milieu-economie, Werkdocument WRR (Den Haag).

Nijkamp, P. and J. Spronk, 1980, Interactive multiple goal programming: An evaluation and some results, in: $G$. Fandel and $T$. Gal, eds., Multiple criteria decision making theory and applications (Springer Verlag, Berlin).

Spronk, J., 1981, Interactive multiple goal programming: Applications to financial planning (Martinus Nijhoff, Boston, MA).

WRR, 1982, Beleidsgerichte toekomst verkenning, deel II (includes an English summary) (Staatsuitgeverij, Den IIaag) forthcoming. 